\title{
Analysis of geophysical methods in the study of fixing production casing leaks in oil wells of Tatarstan
}

\author{
Roza Karimova $^{1 *}$, Svetlana Golub ${ }^{1}$ \\ ${ }^{1}$ State budget educational institution Almetyevsk State Oil Institute 2a Lenina St., Almetyevsk, Republic of Tatarstan, 423458, Russia
}

\begin{abstract}
The paper analyzes field data of the most effective geophysical methods to date to monitor the technical condition of the production casing using examples of wells at the Romashkinskoye oil field in Tatarstan. The results of interpretation according to a flaw detector together with a caliper gauge are presented. The most significant intervals of the column subjected to various stages of corrosion have been identified and described, which allows us to determine and evaluate the size, nature of violations, and to solve the issue of squeeze job.
\end{abstract}

Using geophysical research methods in wells, a wide range of tasks for geological exploration of structure sections, control over the development of oil and gas deposits, and assessment of the technical condition of wells are solved.

Most of the fields in the oil region of Tatarstan have entered the late stage of development, characterized by a large water cut of production wells, significant deterioration of oilfield equipment and leaking casing strings. In this regard, PJSC TATNEFT is increasing capital repairs of wells for environmental reasons, as well as squeeze job to examine the technical condition of the wells, and work to eliminate leakage in the columns. This article analyzes the geophysical methods in the study of production casing leaks in the wells of the Romashkinskoye field.

Among the main causes of changes in the production casing are: metal corrosion due to redox processes, the aggressive effects of highly mineralized Devonian formation waters, the adverse effects of hydrogen sulfide contained in sulfur dioxide; stress from the rock, exceeding the margin of safety of casing pipes. Numerous tripping and tubing operations in the wells cause great damage to the column, where repair work and depressurization of coupling joints are often carried out; low-quality cementing during the final work in the drilling process, as well as blastingperforation operations.

The most acceptable set of methods for determining casing leakage is temperature logging, noise logging, mechanical flow measurement, thermoconductive downhole flowmeter, electromagnetic flaw detection, scanning gamma-gamma defectometer-thickness gauge.

To date, the method of electromagnetic defectoscopy of wells is an effective and used means of monitoring the technical condition of casing wells. Unlike acoustic, radioactive and mechanical methods, it excludes the influence of deposits on the inner surface of the column wall and dense formations behind the column, and it is also possible to study multi-column structures. The method of magnetic pulse defectoscopy is based on the principle of induction pulse sounding, where the excitation and measurement of signals are separated in time. The separation of information in time is due to the presence of many channels of digital recording and signal transmission. The first channels mark the earliest pulse reflections from the inner walls of the first column, and the latest depend on the total amount of metals in the zone in the sensor zone.

The physical basis of the method is as follows. The screening effect of thick metal ferromagnetic pipes is overcome by the pulsed-field excitation and measurement of the response in the pauses between pulses when a strong primary field is turned off and does not interfere with the registration of weak secondary fields. The induction interaction of eddy currents in the central and external tubes gradually during the transition process leads to the fact that they begin to manifest themselves as a single object with total parameters.

Electromagnetic flaw detection is used to transform possible emergencies during drilling and well workover, it is used to distinguish perforation intervals, cut-in boundaries and structural elements, column defects, and allows monitoring of slotted sandblasting. Wall thickness determination data is used to evaluate the residual strength of columns.

Analysis of field data of flaw detection and caliper log measurement was carried out in two wells located at the Romashkinskoye field. A typical example of well 0001 using a flaw detector and caliper for the EMDSMP device and SKPU-4 device in the production casing is shown in Figure 1. 


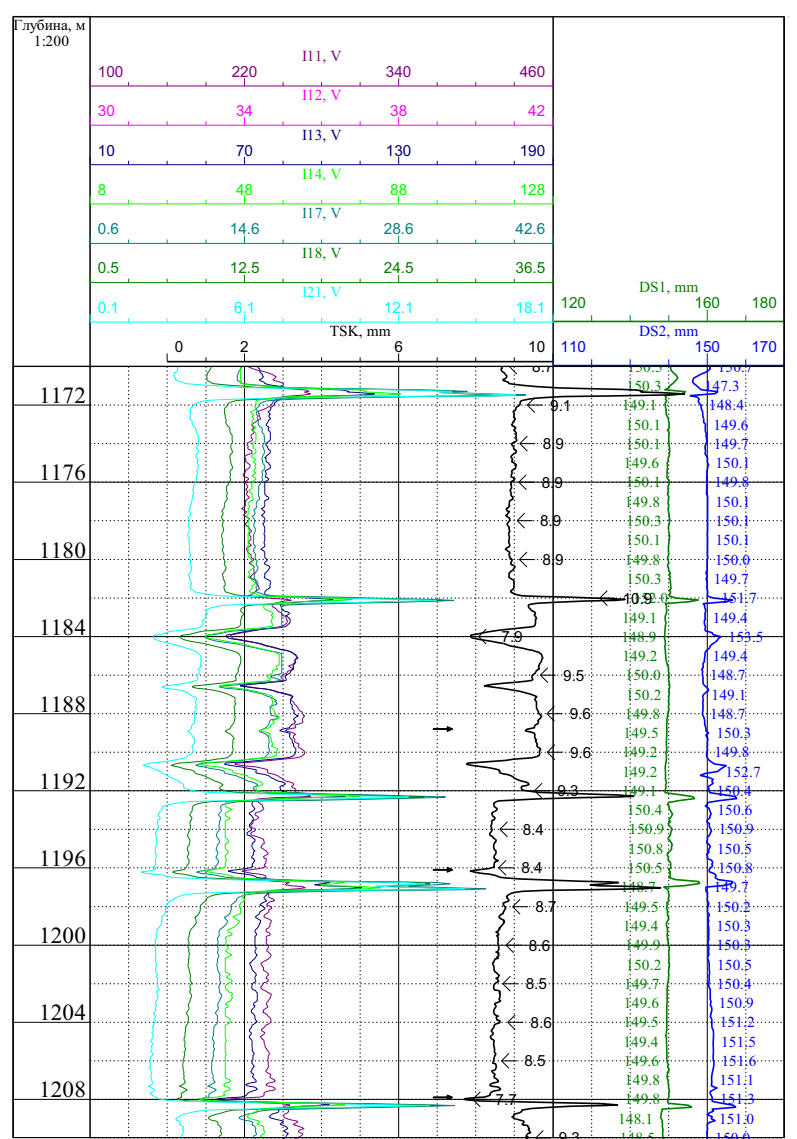

Fig.1. The results of the study of the technical condition of the column by flaw detection and caliper log measurement methods.

In Fig. 1. The following indications are presented:

I10 - I13, I17 - I21 - signal readings along the column,

I25 - signal readings for the entire structure,

TSK - wall thickness e / columns, mm,

DS is the internal diameter of the well (Double Axis Caliper Logging).

Measurement by methods of flaw detection and caliper log measurement was performed on a hard cable. The initial diameter of the column was DS 1 $168 \mathrm{~mm}$. At the time of the study, a change in the diameter of the column was observed. The interpretation results are presented in table 1.

Table 1. Interpretation Results.

\begin{tabular}{|c|c|}
\hline Intervals, $\mathbf{m}$ & Degree of corrosion \\
\hline $1190.2-1192$ & Intense Corrosion Wear \\
\hline $1190.3-1191$ & DS2 internal diameter increase to \\
$152.7 \mathrm{~mm}$
\end{tabular}

Another example of well 0002 is the interpretation of EMF data was performed using the module of the software package "Prime" (Fig.2.).

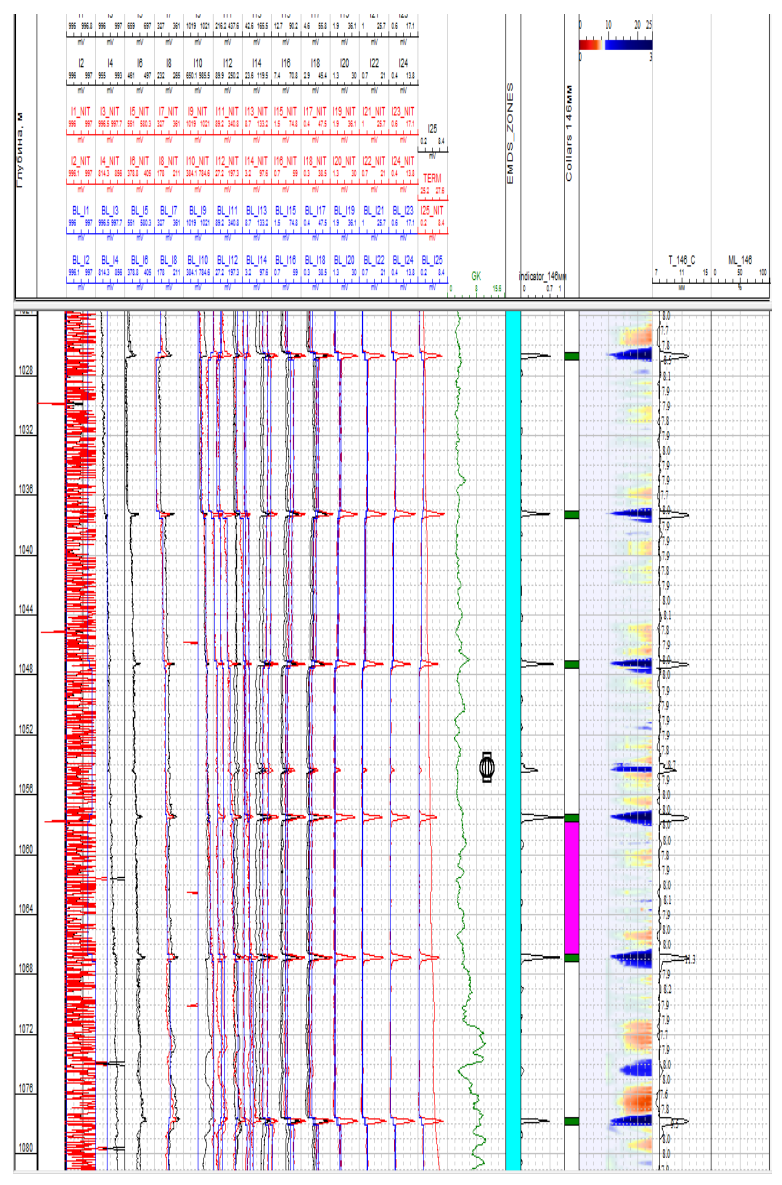

Fig. 2. A fragment of a tablet with the results of the Prime program processing flaw detector data.

The technical capabilities of the Prime program for the flaw detector are displayed in Table 2.

Table 2. Key parameters of the Prime program for the flaw detector.

\begin{tabular}{|c|c|c|}
\hline Parameters & Unit & Description \\
\hline \multicolumn{3}{|l|}{$\mathrm{N}$ inter } \\
\hline OD & $\mathrm{mm}$ & Pipe outer diameter \\
\hline $\begin{array}{l}\text { Interval of } \\
\text { roofing }\end{array}$ & M & Roof depth \\
\hline Interval outsole & $\mathrm{M}$ & Sole depth \\
\hline T_9_Min & $\mathrm{mm}$ & $\begin{array}{l}\text { Minimum wall thickness in } \\
\text { the range }\end{array}$ \\
\hline T_9_Max & $\mathrm{mm}$ & $\begin{array}{l}\text { The maximum wall } \\
\text { thickness in the interval }\end{array}$ \\
\hline T_9_AVG & $\mathrm{mm}$ & $\begin{array}{l}\text { The average wall thickness } \\
\text { in the range }\end{array}$ \\
\hline T_9_N & $\mathrm{mm}$ & $\begin{array}{l}\text { Nominal wall thickness in } \\
\text { the range }\end{array}$ \\
\hline D_MAX_ML & M & $\begin{array}{l}\text { Depth of maximum metal } \\
\text { loss }\end{array}$ \\
\hline MAX_ML & $\%$ & $\begin{array}{l}\text { The maximum percentage of } \\
\text { metal loss at depth }\end{array}$ \\
\hline AVG_ML & $\%$ & $\begin{array}{c}\text { The average value of metal } \\
\text { loss in the interval }\end{array}$ \\
\hline DIF_Tmin & $\mathrm{mm}$ & $\begin{array}{l}\text { The difference between the } \\
\text { nominal and minimum wall } \\
\text { thickness }\end{array}$ \\
\hline level & & $\begin{array}{l}\text { Corrosion level according to } \\
\text { maximum metal loss }\end{array}$ \\
\hline
\end{tabular}


The level of corrosion is also displayed in the data set (Table 3), according to the maximum metal loss (weak, medium, significant, strong, critical) (Table 4). When processing, it is possible to exclude the influence of the perforation interval on the results of the conclusion.

Table 3. Corrosion levels.

\begin{tabular}{|c|c|c|}
\hline Level & Loss of metal,\% & $\begin{array}{c}\text { Level of } \\
\text { corrosion }\end{array}$ \\
\hline A & 0 до 10 & Low \\
\hline В & 11 до 19 & Average \\
\hline C & 20 до 35 & Significant \\
\hline D & 36 до 50 & Strong \\
\hline E & 51 до 100 & Critical \\
\hline
\end{tabular}

For well 0002, the changes presented in Table 4 and Fig. 3.

Table 4. Corrosion data processing results.

\begin{tabular}{|c|c|c|c|c|c|c|c|c|}
\hline $\begin{array}{c}\text { Tne } \\
\text { num } \\
\text { ber } \\
\text { of } \\
\text { the } \\
\text { inter } \\
\text { val }\end{array}$ & OD & $\begin{array}{l}\mathrm{T} \\
\overline{\mathrm{N}}\end{array}$ & $\begin{array}{c}\text { Poof of } \\
\text { the } \\
\text { interval }\end{array}$ & $\begin{array}{l}\text { Bottom } \\
\text { of the } \\
\text { interval }\end{array}$ & $\begin{array}{l}\text { D_MA } \\
\text { X_ML }\end{array}$ & ${ }_{\text {ML }}^{\text {MAX }}$ & $\begin{array}{c}\text { LEV } \\
\text { EL }\end{array}$ & $\begin{array}{c}\mathrm{NOT} \\
\mathrm{E}\end{array} \mid$ \\
\hline 1 & 146 & 7 & 1062,08 & 1070,63 & 3,616 & 3,616 & A & Low \\
\hline 2 & 146 & 7 & 1070,63 & 1081,73 & 6,686 & 3,686 & A & Low \\
\hline 3 & 146 & 7 & 1081,73 & 1092,88 & 3,024 & 3,024 & A & Low \\
\hline 4 & 146 & 7 & 1092,88 & 1103,83 & 3,457 & 3,457 & A & Low \\
\hline 5 & 146 & 7 & 1103,83 & 1115,03 & 12,374 & 12,374 & B & \begin{tabular}{|c|} 
Midd \\
le
\end{tabular} \\
\hline 6 & 146 & 7 & 1115,03 & 1126,03 & 5,102 & 5,102 & A & Low \\
\hline 7 & 146 & 7 & 1126,03 & 1137,18 & 4,082 & 4,082 & A & Low \\
\hline 8 & 146 & 7 & 1137,18 & 1148,58 & 6,333 & 6,333 & A & Low \\
\hline 9 & 146 & 7 & 1448,58 & 1150,98 & 7,843 & 7,483 & A & Low \\
\hline
\end{tabular}

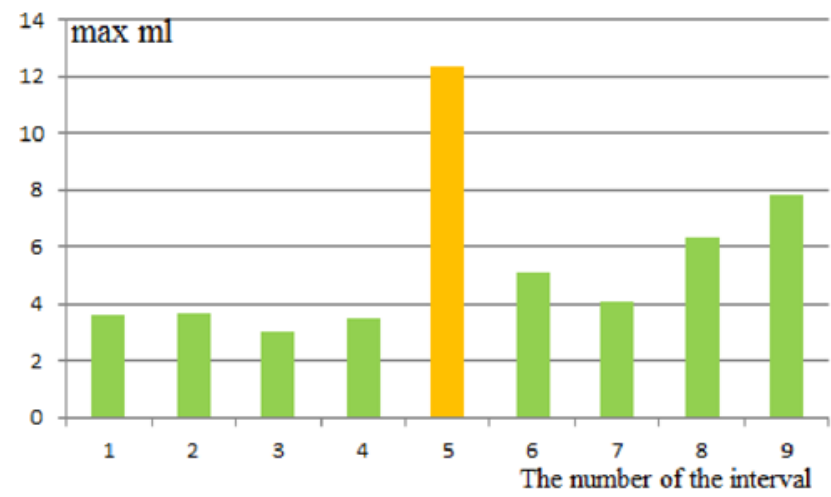

Fig. 3. Histogram of the change in the maximum percentage of metal loss at intervals.

In 1993 in well 0002, the diameter of the electric column was $146 \mathrm{~mm}$, and the nominal wall thickness was $7 \mathrm{~mm}$. At the time of the study, the diameter and wall thickness of the well did not change; the level of corrosion is low and medium. As a result, a conclusion was made on the satisfactory condition of the column

Thus, monitoring the technical condition of the wells allows us to determine the intervals of failure of the integrity of the columns in time, to assess the size and nature of these violations, to repair them in time and thereby reduce the negative consequences of corrosion processes and extend the life of the wells.

\section{References}

1. R.S Khisamov. Fundamentals of field and field geophysics for geologists - Academy of Sciences of the Republic of Tatarstan. Kazan (2013)

2. R.M. Karimova., N.A. Chukhnovskaya Analysis of geophysical methods in the study of casing leakage. Materials of the All-Russian scientificpractical conference "Oil and Gas Complex: Education, Science and Production" March 28 April 1, (2016) I. - Almetyevsk: ASOI Printing House, (2016)

3. R.M. Karimova Possibilities of electromagnetic defectoscopy in the study of casing strings. Materials of the All-Russian scientific-practical conference "Oil and Gas Complex: Education, Science and Production" April 14-18, I. Almetyevsk: ASOI Printing House, (2014)

4. R.M. Karimova, N.A. Chukhnovskaya Investigation of casing violations by fieldgeophysical methods. The collection of materials of the International scientific-practical conference "Achievements, problems, prospects for the development of the oil and gas industry" October 28-29, (2016). I. - Almetyevsk: Printing house ASOI, (2016)

5. A.F. Slivchenko, S.V. Lyubimova, A.A. Zalyatdinov Local sealing technique to improve production string integrity Collected: IOP CONFERENCE SERIES: EARTH AND ENVIRONMENTAL SCIENCE The conference proceedings. Far Eastern Federal University (2019)

6. Khuzina LB, Lyubimova S.V., Slivchenko A.F., Dove S.I., Shaykhutdinova A.F., Latypova R.F. Analysis of tightness of production casing and proposals to increase its effectiveness depending on geological conditions // report on research / development. ASOI. - (2013)

7. Takhautdinov Sh.F., Slivchenko A.F., Zalyatov M.Sh. Technology for overhaul of oil and gas wells. The manual for bachelors of the direction 131000 "Oil and Gas Business" of all forms of training. M.: Publishing house "OIL MANAGEMENT", (2015) 